\title{
Gender Differences in Schizophrenia and First-Episode Psychosis: A Comprehensive Literature Review
}

\author{
Susana Ochoa, ${ }^{1}$ Judith Usall, ${ }^{1}$ Jesús Cobo, ${ }^{2}$ Xavier Labad, ${ }^{3}$ and Jayashri Kulkarni ${ }^{4}$ \\ ${ }^{1}$ Research and Developmental Unit of Parc Sanitari Sant Joan de Déu, CIBERSAM. GTRDSM, Sant Boi de Llobregat, \\ 08330 Barcelona, Spain \\ ${ }^{2}$ Department of Mental Health, Corporació Parc Sanitari Tauli, GTRDSM, Sabadell, 08830 Barcelona, Spain \\ ${ }^{3}$ Department of Mental Health, Institut de Psiquiatria Pere Mata, GTRDSM, Reus, Tarragona, Spain \\ ${ }^{4}$ Monash Alfred Psychiatry Research Centre (MAPrc), "We Mend Minds," Old Baker Building, The Alfred Commercial Road, \\ Melbourne, VIC 3004, Australia
}

Correspondence should be addressed to Susana Ochoa, sochoa@pssjd.org

Received 14 November 2011; Revised 19 January 2012; Accepted 31 January 2012

Academic Editor: David C. Henderson

Copyright (C) 2012 Susana Ochoa et al. This is an open access article distributed under the Creative Commons Attribution License, which permits unrestricted use, distribution, and reproduction in any medium, provided the original work is properly cited.

\begin{abstract}
Recent studies have begun to look at gender differences in schizophrenia and first-episode psychosis in an attempt to explain the heterogeneity of the illness. However, a number of uncertainties remain. This paper tries to summarize the most important findings in gender differences in schizophrenia and first-psychosis episodes. Several studies indicate that the incidence of schizophrenia is higher in men. Most of the studies found the age of onset to be earlier in men than in women. Findings on symptoms are less conclusive, with some authors suggesting that men suffer more negative symptoms while women have more affective symptoms. Premorbid functioning and social functioning seem to be better in females than males. However, cognitive functioning remains an issue, with lack of consensus on differences in neuropsychological profile between women and men. Substance abuse is more common in men than women with schizophrenia and first-episode psychosis. In terms of the disease course, women have better remission and lower relapse rates. Lastly, there is no evidence of specific gender differences in familial risk and obstetric complications. Overall, gender differences have been found in a number of variables, and further study in this area could help provide useful information with a view to improving our care of these patients.
\end{abstract}

\section{Introduction}

Schizophrenia and first-episode psychosis are disorders with considerable heterogeneity in several of its basic features. There is great variability in clinical presentation, disease course, and response to both pharmacological and psychosocial treatment. Some aspects of this heterogeneity may be gender related and, given the reliability, stability, and validity of its definition, study of the gender variable may help explain the differences. Gender differences have been studied extensively in recent decades and although there are definite findings, much uncertainty remains about the extent of the differences. This paper will try to summarize the most relevant research done around the world on gender differences in schizophrenia and first-psychosis episodes. The topics discussed in this paper will be prevalence and incidence, age of onset, symptoms, premorbid, social and cognitive functioning, substance abuse, course of illness, physical health and metabolic complications, and familial risk and obstetric complications. The paper will try to assess gender differences studies on each of these topics in people with schizophrenia and in first-episode psychosis. A greater understanding of the gender differences presents in schizophrenia and first-episode psychosis can help us design more effective preventive and intervention actions.

\section{Prevalence and Incidence of Schizophrenia}

The existence of gender differences in the incidence of schizophrenia has been subject to debate. Traditionally, it was accepted that the incidence and prevalence of schizophrenia was the same in men and women [1]; however, recent studies 
suggest gender differences in the incidence of the illness. Lewine et al. [2] were the first to note that by using more restrictive criteria for the diagnosis of schizophrenia, the number of women excluded from the definition is greater than men. Castle et al. [3] applied a different set of diagnostic criteria to an incidence sample of patients with a wide range of nonaffective psychosis presentations and found that the effect of different diagnostic criteria on the gender ratio is profound. For example, the Feighner restrictive criteria found a ratio of female-men $0.41: 1$ and the ICD the ratio female-men is $0.92: 1$. Using standard diagnostic criteria in an incidence population study, a meta-analysis by Aleman et al. [4] confirmed that the men had a higher incidence (ratio 1.42). However, the recent studies of prevalence of schizophrenia in general population did not find gender differences $[5,6]$. One possible explanation for the disparity between incidence and prevalence could be related to compliance with treatment and higher rates of suicide completion in men than in women [7]. Another possible explanation could be related to the design of the studies, for example, one centered more in epidemiological resources and the incidence was centered in clinical data.

No gender differences have been found in prevalence of schizophrenia in epidemiological studies; however, it seems that more new cases of schizophrenia have been detected in men.

\section{Age of Onset}

Differences in age of onset are the most replicated finding in studies into gender differences in schizophrenia. [8-10] Men usually develop the illness at age 18-25, while in women, the mean age of onset is 25-35. Furthermore, the onset distribution curves for males and females are not isomorphic. Women seem to have two peaks in the age of onset of disease: the first after menarche and the second once they are over 40 $[3,11]$. However, in 1998, Castle et al. found that early-onset age distribution is similar between men and women [12]. The major prevalence of women once they are over 40 years could be explained by the reduction of estrogens after menopause according the estrogenic hypothesis of schizophrenia [13]. However, a number of studies found no gender difference in the age of onset [14-16].

Some authors have suggested that differences in age of onset appear to depend on the presence or absence of family history, with no differences being found between men and women if they had a family history $[17,18]$.

Besides, the findings of early age of onset in men have been replicated in first-episode psychosis $[19,20]$, indicating a consistency with the results found in schizophrenia.

Gender differences have been found in most of the studies done in age of onset in schizophrenia and first-episode psychosis, showing a different profile of onset of illness between women and men.

\section{Symptoms}

The study of gender differences in symptoms of schizophrenia has been one of the most explored issues. However, the results in this area are inconclusive.
Several studies have found gender differences in negative symptoms, showing that in males, they were more severe [21-23]. Moreover, in a sample of 276 people with schizophrenia, Galderisi et al. [10] found that men scored higher in disorganization and negative symptoms. In a large sample of patients with psychosis, Morgan et al. [24] identified a higher prevalence of depressive symptoms and lower prevalence of negative symptoms in women. Higher prevalence of depressive and anxiety symptoms in women had been found in previous studies $[3,25]$.

Nevertheless, most of the studies $[15,26,27]$ found no significant clinical differences in symptoms, [19, 26, 27] which is in line with our team's findings [28].

Results from the assessment of symptoms in first-episode psychosis are also inconclusive. In a group of patients with schizophrenia admitted for the first time, Szymanski et al. [28] found that women presented more anxiety, illogical thinking, inappropriate affect, and bizarre behavior than men. Cotton et al. [29] found that women presented higher levels of affective symptoms than men. However, no gender differences were found in the study by Barajas et al. [30].

In relation to diagnosis, Andia et al. [31] found a higher percentage of women diagnosed with paranoid schizophrenia.

There is not a clear influence of gender in the symptoms presented in people with schizophrenia and first-episode psychosis. However, the studies that found gender differences describe higher presence of negative and disorganization symptoms in men and higher prevalence of affective symptoms in women.

\section{Premorbid Functioning}

Better premorbid functioning has been associated with a better prognosis for the illness. Gender differences here could, therefore, have a bearing on how the schizophrenia evolves. In general, most studies have found gender differences in premorbid functioning, this being worse in men than in women [21, 24, 32-34]. McGlashan and Bardenstein [32] found that women had better premorbid social functioning and marital adjustment. However, in a sample of 113 patients, females and those with a diagnosis of schizoaffective disorder had better premorbid adjustment in the academic domain, but not in the social domain [34].

These results have been replicated in a sample of firstepisode psychosis $[35,36]$. Little is known about gender differences in the psychosis prodromes. In adolescents at ultrahigh-risk (UHR) of imminent onset of psychosis, being female was a significant predictor of conversion to affective psychosis two years after ascertainment [36] and young male adults with a diagnosis of schizotypal disorder had a fourfold risk of conversion to schizophrenia one-year after enrolment when compared to females [36].

In a study by Rachel Willhite with sixty-eight ultra-highrisk patients in California (USA), the authors investigated gender differences in symptoms, functioning, and social support. There were no gender differences in demographic variables, symptoms, or functioning at baseline. Males were found to have significantly higher levels of negative symptoms and 
marginally lower levels of functioning and females reported higher levels of social support at baseline. Differences in negative symptoms were found to mediate differences in functioning between male and female patients. This study suggests that gender-based differences in symptom presentation and functional outcome may predate conversion to psychosis [37].

Also interesting is the association found between worse premorbid adjustment, insidious onset, and negative symptoms $[33,38]$. Thus, one explanation for the worse premorbid functioning in men could be the earlier age of onset.

Most of the literature that assesses premorbid functioning found that women have higher levels of premorbid adjustment and reported higher levels of social support than men.

\section{Social Functioning}

In general, studies that have examined gender differences in social functioning have found better performance in women. Chaves et al. [38] found that women were better adapted and presented less disability than men. In a three-year follow-up study of 86 patients who had a first episode of schizophrenia, using the DAS scale, Vázquez-Barquero et al. [39] found that men had a worse prognosis. A previous study by our group of 239 patients with schizophrenia living in the community also found that men scored higher in disability (measured with the DAS scale) [40, 41]. Vila-Rodriguez et al. [42] replicated these results, finding that women scored higher in social functioning assessed by LSP. Recently, following a 20-year longitudinal study, Grossman et al. [43] found that women had better global functioning over the course of the illness.

However, after assessing the occupation rate and several psychosocial functioning indices (PSP, PSRS, and UPSA-B) in patients with schizophrenia, Galderisi et al. [10] found no gender differences in social outcome. Additionally, in a longterm study (15 years), Bottlender et al. [44] failed to detect gender differences in social disability in patients with schizophrenia, schizoaffective, and affective disorders through the DAS.

In first-episode psychosis, the results obtained by Cotton et al. [29] show that women had higher levels of functioning (assessed by GAF, unemployment index and living with family).

In relation to stressful life events, several studies have found that females need more exposure to stressful life events than males to trigger a psychotic disorder $[45,46]$. It seems that women with schizophrenia presented higher resilience than men to cope with stress situations and women need higher risk factors in order to develop a psychosis than men do.

Regarding the needs of patients with schizophrenia, men presented more basic (accommodation, food, daily activities) and functional needs (education, money, personal care), while women scored higher in the prevalence of service needs (information about the illness, benefits, transport) [47]. This finding indicates that women perform better in basic and functional domains than men, and men should be trained in order to acquire these functional skills.
In relation to fertility, some reports suggest reduced procreation among men with schizophrenia, but the cause is unknown. Male cases were significantly more likely than female cases to be single and childless [48]. In contrast, the Indo-US Project on Schizophrenia Genetics detected that a reproductive deficit observed among US males was not observed among the Indian men. Conjugal status was a significant covariate for reproduction in both samples. The reproductive deficit may be due to difficulties in establishing long-term conjugal relationships among the US men and not in the Indian sample. According to the authors, the differences may also reflect underlying cultural variations related to marital practices [49].

Women with schizophrenia and first-episode psychosis performed better in social functioning according to objective assessments (fertility, being married) and social scales assessment. Moreover, women presented less basic and functional needs and need more exposure to life events in order to develop a psychosis illness.

\section{Cognitive Functioning}

Gender differences in cognitive domains have been another controversial issue. A number of authors have demonstrated that men score worse in attention, language, and executive function than women [50-53]. Vaskinn et al. [54] suggest better functioning in neuropsychological performance in women than men, except in the category of attention. Bozikas et al. [55] found that women performed better than men in verbal learning and memory.

Bilder et al. [56] found that males performed better in the information subtest of the WAIS, while women performed better in the Digit Symbol subtest. Other studies have shown cognitive functioning to be worse in women with schizophrenia than men $[57,58]$.

In the study by Karilampi et al. [59], better cognitive function was predicted by higher psychosocial functioning levels in males but by lower symptom levels in females, suggesting a slight difference between women and men in the domains relating to cognitive function, which need to be taken into account.

Other studies, however, found no gender difference in the assessment of cognitive domains [60-62].

Gender differences in cognitive function in people with schizophrenia remained controversial. The studies that found gender differences indicate higher levels of functioning in women especially in the language, executive, and memory domains.

\section{Substance Abuse}

Substance abuse presented a higher prevalence in people with schizophrenia and first-episode psychosis [63-65]. The rates indicated that men consume more cannabis than women [64, 66]. In the case of first-episode psychosis, men had a higher prevalence of cannabis use than women [29, 64, 66, 67]. Moreover, Rodríguez-Jiménez et al. [68] found that men have higher comorbidity of cocaine and hallucinogen use and 
of cannabis use than women. In the case of alcohol abuse, the data show that males present higher levels of consumption than women [10].

In addition, Arendt et al. [69] demonstrate that the risk of developing psychosis is higher in men who consume cannabis than women. The study assessed a total of 535 people with a cannabis-induced psychosis over three years, and the rates for developing schizophrenia were $47.6 \%$ in males versus $29.8 \%$ in women.

Men presented higher prevalence of substance abuse and higher levels of comorbidity than women. Moreover, it seems that substance abuse could be a risk factor for developing psychosis in males.

\section{The Course of the Illness}

The disease course for schizophrenia has been reported as following different patterns in males and females. Uggerby et al. [70] studied the prevalence of institutionalized and noninstitutionalized people with schizophrenia in Denmark in a sample of 22,395 people. The results showed that being male was one of the predictors of institutionalization. Gender has also been identified as one of the factors influencing clinical remission, with relapse rates being higher in men and remission rates higher in women [71].

With regard to hospitalizations, Usall et al. [40] found that the number of previous hospitalizations was similar for both men and women. However, women required less time in hospital than men at baseline. After a three-year followup of these patients, the results indicated that women had fewer admissions than men and the length of stay was shorter (men, 40 days versus women, 5.8) [72]. In the SOHO Study, however, Haro et al. [71] found that women presented a higher risk of hospitalization than men.

The efficacy and tolerance of the different antipsychotic treatments may be gender-sensitive. Most studies found that women respond better to typical antipsychotics $[28,73]$ and olanzapine $[74,75]$ The results for clozapine are more controversial [75-77]; as for risperidone, the few studies in this direction have not found differences [78]. Premenopausal women had a significantly better treatment response to olanzapine than postmenopausal women, regardless of chronicity and treatment [74].

No significant gender differences were found, either in treatment response or neurological side effects, in patients treated with risperidone [78]. There were, however, some concerns about parkinsonian symptoms with atypical neuroleptics being more frequent in women [79].

The results found regarding course of illness are controversial; however, it seems that women presented higher rates of remission, less days of hospitalization, and better response to typical antipsychotics than men.

\section{Physical Health and Metabolic Complications}

There have also been concerns about gender differences in relation to physical health and metabolic complications in psychosis.
The metabolic impact of antipsychotic treatments in women (and men) is significant. Atypical and older antipsychotics are very useful drugs, but they can be associated with hyperprolactinemia and related disorders. These endocrine aspects are particularly significant. Women have greater metabolic and endocrine-induced antipsychotic side effects. In fact, every woman exposed to atypical antipsychotics is at risk of developing hyperprolactinemia-related problems, particularly young women [80-82]. Previous studies have consistently reported a higher prevalence of hyperprolactinemia in women receiving antipsychotics, and cross-sectional studies in the USA and UK have estimated hyperprolactinemia prevalence rates of up to $42 \%$ in men and $75 \%$ in women with schizophrenia who were receiving conventional antipsychotics or risperidone $[83,84]$. It is known that hyperprolactinemia is associated with a number of physical health problems in males and females, particularly endocrine and immunological system changes, as well as growth hormone alterations. For example, in one study which included 150 women, $14 \%$ were observed to develop galactorrhea within 75 days of initiating treatment with conventional antipsychotics [85]. Hyperprolactinemia affects long-term health in women. Menstrual irregularities have been found in up to $48 \%$ of women receiving antipsychotic treatment $[80,82]$. Reduced bone mineral density has been demonstrated in $57 \%$ of men and $32 \%$ of women treated with prolactinraising antipsychotics for over 10 years [86]. One case-control study investigated whether potential treatment-emergent decreases in bone mineral density could confer an increased risk of hip fractures in patients with a history of schizophrenia [87].

Although sexual dysfunction appears to be inherent to the illness in patients with schizophrenia, it is also frequently reported during antipsychotic treatment, with interesting gender differences. More than $50 \%$ of males and $30 \%$ of females have been shown to experience sexual dysfunction during conventional antipsychotic treatment. This specific secondary effect may be relevant to adherence in some patients $[88,89]$.

A Spanish national cross-sectional study in 733 patients diagnosed with schizophrenia on treatment with second generation antipsychotics and admitted to short-stay hospital units detected different cardiovascular risk factors in women than in men. Men were treated for hypertension $(\mathrm{OR}=25.34$, $P<0.03)$ and women for diabetes $(\mathrm{OR}=0.02, P<0.03)$ [90].

Metabolic syndrome is associated with the development of coronary heart disease and diabetes mellitus. A higher presence of metabolic syndrome has been detected in females. In a Turkish sample, Boke et al. found that $61.4 \%$ of females, but only $22.4 \%$ of males, had metabolic syndrome [91].

The prevalence of metabolic syndrome in 1460 US patients from the Clinical Antipsychotic Trials of Intervention Effectiveness (CATIE) showed important gender differences. In females, depending on the criteria used, it was $51.6 \%$ (NCEP) or $54.2 \%$ (AHA), compared to $36.0 \%$ (NCEP; $P=$ 0.0002 ) or $36.6 \%$ (AHA; $P=0.0003$ ) for males. $73.4 \%$ of all females (including nonfasting subjects) met the waist 
circumference criterion compared to $36.6 \%$ of males. In a logistic regression model with age, race, and ethnicity as covariates, CATIE males were $138 \%$ more likely to have metabolic syndrome than a general population-matched sample (NHANES), and CATIE females, 251\% more likely than their general-population counterparts. Even when controlling for differences in body mass index, CATIE males were still $85 \%$ more likely to have MS than the NHANES male sample and CATIE females, $137 \%$ more likely to have MS than females in NHANES [92].

In contrast, in a study devoted to detect coronary heart disease risk and prevalence of metabolic syndrome in $268 \mathrm{pa}-$ tients with schizoaffective disorder receiving antipsychotics, the authors detected no gender differences, but coronary heart disease risk and prevalence of metabolic syndrome were higher among patients with schizoaffective disorder. The prevalence of metabolic syndrome was associated with age and severity of disease, but not with gender [93].

Individuals with nonaffective psychosis appear to have an increased prevalence of abnormal glucose tolerance prior to antipsychotic treatment, but this predisposition also appears not to be gender sensitive [94]. Similarly, a large community study in Ontario (Canada) with 1123 schizophrenic outpatients failed to detect gender differences in dysglycemia [95].

Regarding metabolic and endocrine-induced antipsychotic side effect, women presented higher prevalence of symptoms. Hyperprolactinemia and diabetes are more present in women, while hypertension is more prevalent in men with schizophrenia.

\section{Familial Risk and Obstetric Complications}

Various studies have found a higher risk of schizophrenia in relatives of women than in relatives of men [96-98].

However, Kendler and Walsh found no gender differences in the familial risk of schizophrenia [99]. These authors studied familial risk in a sample of 354 first-degree relatives of patients with schizophrenia from the Roscommon Family Study who were interviewed personally. It also explored the possible association between age at onset, gender, and familial risk. The results of Pulver and Liang [97] showed that relatives of men with schizophrenia who have an age of onset under 17 have a significantly higher risk of schizophrenia. However, the authors also found an association between age at onset of schizophrenia and familial risk in women. Other studies have found no interaction between age of onset, gender, and familial risk [100].

Results on whether gender differences exist in the incidence of obstetric complications in patients who will develop schizophrenia have been inconsistent. Some studies have found more obstetric complications in men [101, 102]. However, other studies have found no gender differences $[103,104]$ and others still have found more obstetric complications in women [105]. The influence of gender in the prevalence of obstetric complications, therefore, remains unclear.

Women need higher presence of familial risk than men in order to develop the illness. However, there are not clear results about the influence of gender in the number of obstetric complications.

\section{Conclusions}

In conclusion, although the extent of gender differences in schizophrenia and first-episode psychosis is a controversial issue, this paper discusses some of the most replicated gender differences in schizophrenia and first-episode psychosis. Several studies indicate that schizophrenia and first-episode psychosis are less incident in women than in men but, in the case of women, it seems that the prognosis of the illness, the social functioning and the response to treatment is better. According to most of the studies revised, one possible explanation of this better adjustment could be that women presented a higher age of onset than men, which allows them to adjust better to the requirements of the community. The estrogen hypothesis tries to explain why women have a later age of the onset. According to this hypothesis some therapeutic treatments associated with estrogens could be useful for improving symptoms and cognition, especially in women. Moreover, the review shows us that women need more risk factors in order to develop schizophrenia than men (more familial risk, more presence of life events). This findings are in agreement with the neurodevelopment hypothesis, where men seem to present a more deteriorated profile than women before the onset of the illness.

One of the limitations of this paper is that, given the breadth of the subject, some issues have not been commented. Social influence of the context and the fact that most of the studies have been done in developed countries is a clear limitation that should be taken into account in the future.

From the reviewed literature, we conclude that women with schizophrenia perform better in several areas than men; however, future research should be addressed to study gender differences to clarify the remaining controversial issues. Novel sex-specific treatments could be developed to better meet the needs of people with schizophrenia and first-episode psychosis.

\section{References}

[1] R. J. Wyatt, R. C. Alexander, M. F. Egan, and D. G. Kirch, "Schizophrenia, just the facts. What do we know, how well do we know it?" Schizophrenia Research, vol. 1, no. 1, pp. 3-18, 1988.

[2] R. Lewine, D. Burbach, and H. Y. Meltzer, "Effect of diagnostic criteria on the ratio of male to female schizophrenic patients," American Journal of Psychiatry, vol. 141, no. 1, pp. 8487, 1984.

[3] D. J. Castle, S. Wessely, and R. M. Murray, "Sex and schizophrenia: effects of diagnostic stringency, and associations with premorbid variables," British Journal of Psychiatry, vol. 162, pp. 658-664, 1993.

[4] A. Aleman, R. S. Kahn, and J. P. Selten, "Sex differences in the risk of schizophrenia: evidence from meta-analysis," Archives of General Psychiatry, vol. 60, no. 6, pp. 565-571, 2003.

[5] J. Perälä, J. Suvisaari, S. I. Saarni et al., "Lifetime prevalence of psychotic and bipolar I disorders in a general population," Archives of General Psychiatry, vol. 64, no. 1, pp. 19-28, 2007. 
[6] J. McGrath, S. Saha, D. Chant, and J. Welham, "Schizophrenia: a concise overview of incidence, prevalence, and mortality," Epidemiologic Reviews, vol. 30, no. 1, pp. 67-76, 2008.

[7] M. A. Test, S. Senn Burke, and L. S. Wallisch, "Gender differences of young adults with schizophrenic disorders in community care," Schizophrenia Bulletin, vol. 16, no. 2, pp. 331-334, 1990.

[8] J. M. Goldstein, M. T. Tsuang, and S. V. Faraone, "Gender and schizophrenia: implications for understanding the heterogeneity of the illness," Psychiatry Research, vol. 28, no. 3, pp. 243-253, 1989.

[9] O. Gureje, "Gender and schizophrenia: age at onset and sociodemographic attributes," Acta Psychiatrica Scandinavica, vol. 83, no. 5, pp. 402-405, 1991.

[10] S. Galderisi, P. Bucci, A. Uçok, and J. Peuskens, "No gender differences in social outcome in patients suffering from schizophrenia," European Psychiatry. In press.

[11] S. Ochoa, J. Usall, V. Villalta-Gil et al., "Influence of age at onset on social functioning in outpatients with schizophrenia," European Journal of Psychiatry, vol. 20, no. 3, pp. 157-163, 2006.

[12] D. Castle, P. Sham, and R. Murray, "Differences in distribution of ages of onset in males and females with schizophrenia," Schizophrenia Research, vol. 33, no. 3, pp. 179-183, 1998.

[13] A. Riecher-Rossler, H. Hafner, M. Stumbaum, K. Maurer, and R. Schmidt, "Can estradiol modulate schizophrenic symptomatology?” Schizophrenia Bulletin, vol. 20, no. 1, pp. 203 214, 1994.

[14] Z. Folnegovic and V. Folnegovic-Smalc, "Schizophrenia in Croatia: age of onset differences between males and females," Schizophrenia Research, vol. 14, no. 1, pp. 83-91, 1994.

[15] D. Addington, J. Addington, and S. Patten, "Gender and affect in schizophrenia," Canadian Journal of Psychiatry, vol. 41, no. 5, pp. 265-268, 1996.

[16] H. Naqvi, M. M. Kahn, and A. Faizi, "Gender differences in age at onset of schizophrenia," Journal of the College of Physicians and Surgeons Pakistan, vol. 15, no. 6, pp. 345-348, 2005.

[17] M. Albus, J. Scherer, S. Hueber et al., "The impact of familial loading on gender differences in age at onset of schizophrenia," Acta Psychiatrica Scandinavica, vol. 89, no. 2, pp. 132-134, 1994.

[18] H. Häfner, K. Maurer, W. Löffler et al., "The ABC schizophrenia study: a preliminary overview of the results," Social Psychiatry and Psychiatric Epidemiology, vol. 33, no. 8, pp. 380386, 1998.

[19] T. K. Larsen, T. H. McGlashan, and L. C. Moe, "First-episode schizophrenia-I. Early course parameters," Schizophrenia Bulletin, vol. 22, no. 2, pp. 241-256, 1996.

[20] H. Häfner, W. An Der Heiden, S. Behrens et al., "Causes and consequences of the gender difference in age at onset of schizophrenia," Schizophrenia Bulletin, vol. 24, no. 1, pp. 99113, 1998.

[21] D. L. Shtasel, R. E. Gur, F. Gallacher, C. heimberg, and R. C. Gur, "Gender differences in the clinical expression of schizophrenia," Schizophrenia Research, vol. 7, no. 3, pp. 225-231, 1992.

[22] P. E. Cowell, D. J. Kostianovsky, R. C. Gur, B. I. Turetsky, and R. E. Gur, "Sex differences in neuroanatomical and clinical correlations in schizophrenia," American Journal of Psychiatry, vol. 153, no. 6, pp. 799-805, 1996.

[23] A. Riecher-Rössler and H. Häfner, "Gender aspects in schizophrenia: bridging the border between social and biological psychiatry," Acta Psychiatrica Scandinavica, vol. 102, no. 407, pp. 58-62, 2000.

[24] V. A. Morgan, D. J. Castle, and A. V. Jablensky, "Do women express and experience psychosis differently from men? Epidemiological evidence from the Australian National Study of Low Prevalence (Psychotic) Disorders," Australian and New Zealand Journal of Psychiatry, vol. 42, no. 1, pp. 74-82, 2008.

[25] E. Walker, B. A. Bettes, E. L. Kain, and P. Harvey, "Relationship of gender and marital status with symptomatology in psychotic patients," Journal of Abnormal Psychology, vol. 94, no. 1, pp. 42-50, 1985.

[26] E. Lindstrom and L. Von Knorring, "Symptoms in schizophrenic syndromes in relation to age, sex, duration of illness and number of previous hospitalizations," Acta Psychiatrica Scandinavica, vol. 89, no. 4, pp. 274-278, 1994.

[27] N. Hayashi, Y. Igarashi, M. Yamashina, and K. Suda, "Is there a gender difference in a factorial structure of the positive and negative syndrome scale? A test by structural equation modeling," Psychopathology, vol. 35, no. 1, pp. 28-35, 2002.

[28] S. Szymanski, J. A. Lieberman, J. M. Alvir et al., "Gender differences in onset of illness, treatment response, course, and biologic indexes in first-episode schizophrenic patients," American Journal of Psychiatry, vol. 152, no. 5, pp. 698-703, 1995.

[29] S. M. Cotton, M. Lambert, B. G. Schimmelmann et al., "Gender differences in premorbid, entry, treatment, and outcome characteristics in a treated epidemiological sample of 661 patients with first episode psychosis," Schizophrenia Research, vol. 114, no. 1-3, pp. 17-24, 2009.

[30] A. Barajas, I. Baños, S. Ochoa et al., "Age of onset of a first psychotic episode: are there any clinical differences between men and women?" Psiquiatria Biologica, vol. 14, no. 4, pp. 136-141, 2007.

[31] A. M. Andia, S. Zisook, R. K. Heaton et al., "Gender differences in schizophrenia," Journal of Nervous and Mental Disease, vol. 183, no. 8, pp. 522-528, 1995.

[32] T. H. McGlashan and K. K. Bardenstein, "Gender differences in affective, schizoaffective, and schizophrenic disorders," Schizophrenia Bulletin, vol. 16, no. 2, pp. 319-329, 1990.

[33] S. E. Childers and C. M. Harding, "Gender, premorbid social functioning, and long-term outcome in DSM-III schizophrenia," Schizophrenia Bulletin, vol. 16, no. 2, pp. 309-318, 1990.

[34] R. M. G. Norman, A. K. Malla, R. Manchanda, and L. Townsend, "Premorbid adjustment in first episode schizophrenia and schizoaffective disorders: a comparison of social and academic domains," Acta Psychiatrica Scandinavica, vol. 112, no. 1, pp. 30-39, 2005.

[35] G. P. Amminger, S. Leicester, A. R. Yung et al., "Early-onset of symptoms predicts conversion to non-affective psychosis in ultra-high risk individuals," Schizophrenia Research, vol. 84, no. 1, pp. 67-76, 2006.

[36] M. Nordentoft, A. Thorup, L. Petersen et al., “Transition rates from schizotypal disorder to psychotic disorder for first-contact patients included in the OPUS trial. A randomized clinical trial of integrated treatment and standard treatment," Schizophrenia Research, vol. 83, no. 1, pp. 29-40, 2006.

[37] R. K. Willhite, T. A. Niendam, C. E. Bearden, J. Zinberg, M. P. O'Brien, and T. D. Cannon, "Gender differences in symptoms, functioning and social support in patients at ultra-high risk for developing a psychotic disorder," Schizophrenia Research, vol. 104, no. 1-3, pp. 237-245, 2008. 
[38] A. C. Chaves, M. V. Seeman, J. J. Mari, and A. Maluf, "Schizophrenia: impact of positive symptoms on gender social role," Schizophrenia Research, vol. 11, no. 1, pp. 41-45, 1993.

[39] J. L. Vázquez-Barquero, M. J. Cuesta, S. H. Castanedo, I. Lastra, A. Herrán, and G. Dunn, "Cantabria first-episode schizophrenia study: three-year follow-up," British Journal of Psychiatry, vol. 174, pp. 141-149, 1999.

[40] J. Usall, S. Araya, S. Ochoa, E. Busquets, A. Gost, and M. Márquez, "Gender differences in a sample of schizophrenic outpatients," Comprehensive Psychiatry, vol. 42, no. 4, pp. 301-305, 2001.

[41] J. Usall, J. M. Haro, S. Ochoa, M. Márquez, S. Araya, and NEDES Group (Assessment Research Group in schizophrenia), "Influence of gender on social outcome in schizophrenia," Acta Psychiatrica Scandinavica, vol. 106, pp. 337-342, 2002.

[42] F. Vila-Rodriguez, S. Ochoa, J. Autonell, J. Usall, and J. M. Haro, "Complex interaction between symptoms, social factors, and gender in social functioning in a community-dwelling sample of schizophrenia," Psychiatric Quarterly, vol. 82, no. 4, pp. 261-274, 2011.

[43] L. S. Grossman, M. Harrow, C. Rosen, R. Faull, and G. P. Strauss, "Sex differences in schizophrenia and other psychotic disorders: a 20-year longitudinal study of psychosis and recovery," Comprehensive Psychiatry, vol. 49, no. 6, pp. 523529, 2008.

[44] R. Bottlender, A. Strauß, and H. J. Möller, "Social disability in schizophrenic, schizoaffective and affective disorders 15 years after first admission," Schizophrenia Research, vol. 116, no. 1, pp. 9-15, 2010.

[45] D. M. Almeida and R. C. Kessler, "Everyday stressors and gender differences in daily distress," Journal of Personality and Social Psychology, vol. 75, no. 3, pp. 670-680, 1997.

[46] I. Myin-Germeys, L. Krabbendam, P. A. E. G. Delespaul, and J. Van Os, "Sex differences in emotional reactivity to daily life stress in psychosis," Journal of Clinical Psychiatry, vol. 65, no. 6, pp. 805-809, 2004.

[47] S. Ochoa, J. Usall, J. M. Haro et al., "Estudio comparativo de las necesidades de las personas con esquizofrenia en función del género," Actas Españolas de Psiquiatría, vol. 29, no. 3, pp. 165-171, 2001.

[48] P. Thomas, J. Wood, A. Chandra, V. L. Nimgaonkar, and S. N. Deshpande, "Differences among men and women with schizophrenia: a study of US and Indian samples," Psychiatry Investigation, vol. 7, no. 1, pp. 9-16, 2010.

[49] T. Bhatia, M. A. Franzos, J. A. Wood, V. L. Nimgaonkar, and S. N. Deshpande, "Gender and procreation among patients with schizophrenia," Schizophrenia Research, vol. 68, no. 2-3, pp. 387-394, 2004.

[50] J. M. Goldstein, L. J. Seidman, S. Santangelo, P. H. Knapp, and M. T. Tsuang, "Are schizophrenic men at higher risk for developmental deficits than schizophrenic women? Implications for adult neuropsychological functions," Journal of Psychiatric Research, vol. 28, no. 6, pp. 483-498, 1994.

[51] L. J. Seidman, J. M. Goldstein, J. M. Goodman et al., "Sex differences in olfactory identification and Wisconsin card sorting performance in schizophrenia: relationship to attention and verbal ability," Biological Psychiatry, vol. 42, no. 2, pp. 104-115, 1997.

[52] J. M. Goldstein, L. J. Seidman, J. M. Goodman et al., "Are there sex differences in neuropsychological functions among patients with schizophrenia?" American Journal of Psychiatry, vol. 155, no. 10, pp. 1358-1364, 1998.
[53] A. L. Hoff, M. Wieneke, W. O. Faustman et al., "Sex differences in neuropsychological functioning of first-episode and chronically III schizophrenic patients," American Journal of Psychiatry, vol. 155, no. 10, pp. 1437-1439, 1998.

[54] A. Vaskinn, K. Sundet, C. Simonsen, T. Hellvin, I. Melle, and O. A. Andreassen, "Sex differences in neuropsychological performance and social functioning in schizophrenia and bipolar disorder," Neuropsychology, vol. 25, no. 4, pp. 499510, 2011.

[55] V. P. Bozikas, M. H. Kosmidis, A. Peltekis et al., "Sex differences in neuropsychological functioning among schizophrenia patients," Australian and New Zealand Journal of Psychiatry, vol. 44, no. 4, pp. 333-341, 2010.

[56] R. M. Bilder, L. Lipschutz-Broch, G. Reiter, S. H. Geisler, D. I. Mayerhoff, and J. A. Lieberman, "Intellectual deficits in firstepisode schizophrenia: evidence for progressive deterioration," Schizophrenia Bulletin, vol. 18, no. 3, pp. 437-448, 1992.

[57] D. Perlick, S. Mattis, P. Stastny, and J. Teresi, "Gender differences in cognition in schizophrenia," Schizophrenia Research, vol. 8, no. 1, pp. 69-73, 1992.

[58] R. R. J. Lewine, E. F. Walker, R. Shurett, J. Caudle, and C. Haden, "Sex differences in neuropsychological functioning among schizophrenic patients," American Journal of Psychiatry, vol. 153, no. 9, pp. 1178-1184, 1996.

[59] U. Karilampi, L. Helldin, and T. Archer, "Cognition and global assessment of functioning in male and female outpatients with schizophrenia spectrum disorders," Journal of Nervous and Mental Disease, vol. 199, no. 7, pp. 445-448, 2011.

[60] T. E. Goldberg, J. M. Gold, E. F. Torrey, and D. R. Weinberger, "Lack of sex differences in the neuropsychological performance of patients with schizophrenia," American Journal of Psychiatry, vol. 152, no. 6, pp. 883-888, 1995.

[61] R. K. R. Salokangas, "Prognostic implications of the sex of schizophrenic patients," British Journal of Psychiatry, vol. 142, no. 2, pp. 145-151, 1983.

[62] P. J. Moriarty, D. Lieber, A. Bennett et al., "Gender differences in poor outcome patients with lifelong schizophrenia," Schizophrenia Bulletin, vol. 27, no. 1, pp. 103-113, 2001.

[63] D. Wade, S. Harrigan, J. Edwards, P. M. Burgess, G. Whelan, and P. D. McGorry, "Substance misuse in first-episode psychosis: 15-month prospective follow-up study," British Journal of Psychiatry, vol. 189, pp. 229-234, 2006.

[64] T. R. E. Barnes, S. H. Mutsatsa, S. B. Hutton, H. C. Watt, and E. M. Joyce, "Comorbid substance use and age at onset of schizophrenia," British Journal of Psychiatry, vol. 188, pp. 237-242, 2006.

[65] M. T. Compton, M. E. Kelley, C. E. Ramsay et al., "Association of pre-onset cannabis, alcohol, and tobacco use with age at onset of prodrome and age at onset of psychosis in firstepisode patients," American Journal of Psychiatry, vol. 166, no. 11, pp. 1251-1257, 2009.

[66] D. J. Foti, R. Kotov, L. T. Guey, and E. J. Bromet, "Cannabis use and the course of schizophrenia: 10-year follow-up after first hospitalization," American Journal of Psychiatry, vol. 167, no. 8, pp. 987-993, 2010.

[67] M. Hambrecht and H. Häfner, "Cannabis, vulnerability, and the onset of schizophrenia: an epidemiological perspective," Australian and New Zealand Journal of Psychiatry, vol. 34, no. 3, pp. 468-475, 2000.

[68] R. Rodríguez-Jiménez, M. Aragüés, M. A. Jiménez-Arriero et al., "Dual diagnosis in psychiatric inpatients: prevalence and general characteristics," Investigacion Clinica, vol. 49, no. 2, pp. 195-205, 2008. 
[69] M. Arendt, R. Rosenberg, L. Foldager, G. Perto, and P. MunkJørgensen, "Cannabis-induced psychosis and subsequent schizophrenia-spectrum disorders: follow-up study of 535 incident cases," British Journal of Psychiatry, vol. 187, pp. 510-515, 2005.

[70] P. Uggerby, R. E. Nielsen, C. U. Correll, and J. Nielsen, “Characteristics and predictors of long-term institutionalization in patients with schizophrenia," Schizophrenia Research, vol. 131, no. 1-3, pp. 120-126, 2011.

[71] J. M. Haro, A. Ciudad, J. Alonso et al., "Remission and relapse in the ambulatory treatment of patients with schizophrenia. Outcomes at 3 years," Actas Espanolas de Psiquiatria, vol. 36, no. 4, pp. 187-196, 2008.

[72] J. Usall, S. Ochoa, S. Araya, and M. Márquez, "Gender differences and outcome in schizophrenia: a 2-year follow-up study in a large community sample," European Psychiatry, vol. 18, no. 6, pp. 282-284, 2003.

[73] M. V. Seeman, "Neuroleptic prescriptions for men and women," Social Pharmacology, vol. 3, pp. 219-236, 1989.

[74] J. M. Goldstein, L. S. Cohen, N. J. Horton et al., "Sex differences in clinical response to olanzapine compared with haloperidol," Psychiatry Research, vol. 110, no. 1, pp. 27-37, 2002.

[75] J. Usall, D. Suarez, and J. M. Haro, "Gender differences in response to antipsychotic treatment in outpatients with schizophrenia," Psychiatry Research, vol. 153, no. 3, pp. 225-231, 2007.

[76] P. J. Perry, D. D. Miller, S. V. Arndt, and R. J. Cadoret, “Clozapine and norclozapine plasma concentrations and clinical response of treatment-refractory schizophrenic patients," American Journal of Psychiatry, vol. 148, no. 2, pp. 231-235, 1991.

[77] S. Szymanski, J. Lieberman, S. Pollack et al., "Gender differences in neuroleptic nonresponsive clozapine-treated schizophrenics," Biological Psychiatry, vol. 39, no. 4, pp. 249-254, 1996.

[78] A. Labelle, M. Light, and F. Dunbar, "Risperidone treatment of outpatients with schizophrenia: no evidence of sex differences in treatment response," Canadian Journal of Psychiatry, vol. 46, no. 6, pp. 534-541, 2001.

[79] P. Seeman, "Atypical neuroleptics: role of multiple receptors, endogenous dopamine, and receptor linkage," Acta Psychiatrica Scandinavica, vol. 82, no. 358, pp. 14-20, 1990.

[80] S. M. Dursun, H. J. Wildgust, P. Strickland, G. M. Goodwin, L. Citrome, and M. Lean, "The emerging physical health challenges of antipsychotic associated hyperprolactinaemia in patients with serious mental illness," Journal of Psychopharmacology, vol. 22, no. 2, supplement, pp. 3-5, 2008.

[81] P. M. Haddad and A. Wieck, "Antipsychotic-induced hyperprolactinaemia: mechanisms, clinical features and management," Drugs, vol. 64, no. 20, pp. 2291-2314, 2004.

[82] V. O'Keane, “Antipsychotic-induced hyperprolactinaemia, hypogonadism and osteoporosis in the treatment of schizophrenia," Journal of Psychopharmacology, vol. 22, no. 2, pp. 70-75, 2008.

[83] B. J. Kinon, J. A. Gilmore, H. Liu, and U. M. Halbreich, "Prevalence of hyperprolactinemia in schizophrenic patients treated with conventional antipsychotic medications or risperidone," Psychoneuroendocrinology, vol. 28, no. 2, supplement, pp. 55-68, 2003.

[84] S. M. Smith, V. O'Keane, and R. Murray, "Sexual dysfunction in patients taking conventional antipsychotic medication," British Journal of Psychiatry, vol. 181, pp. 49-55, 2002.
[85] K. Windgassen, U. Wesselmann, and H. Schulze Mönking, "Galactorrhea and hyperprolactinemia in schizophrenic patients on neuroleptics: frequency and etiology," Neuropsychobiology, vol. 33, no. 3, pp. 142-146, 1996.

[86] A. M. Meaney, S. Smith, O. D. Howes, M. O’Brien, R. M. Murray, and V. O'Keane, "Effects of long-term prolactinraising antipsychotic medication an bone mineral density in patients with schizophrenia," British Journal of Psychiatry, vol. 184, pp. 503-508, 2004.

[87] L. Howard, G. Kirkwood, and M. Leese, "Risk of hip fracture in patients with a history of schizophrenia," British Journal of Psychiatry, vol. 190, pp. 129-134, 2007.

[88] A. M. Ghadirian, G. Chouinard, and L. Annable, "Sexual dysfunction and plasma prolactin levels in neuroleptictreated schizophrenic outpatients," Journal of Nervous and Mental Disease, vol. 170, no. 8, pp. 463-467, 1982.

[89] A. L. Montejo, "Prolactin awareness: an essential consideration for physical health in schizophrenia," European Neuropsychopharmacology, vol. 18, supplement, pp. S108-S114, 2008.

[90] J. Bobes, C. Arango, P. Aranda, R. Carmena, M. GarciaGarcia, and J. Rejas, "Cardiovascular and metabolic risk in outpatients with schizophrenia treated with antipsychotics: results of the CLAMORS Study," Schizophrenia Research, vol. 90, no. 1-3, pp. 162-173, 2007.

[91] O. Boke, S. Aker, G. Sarisoy, E. B. Saricicek, and A. R. Sahin, "Prevalence of metabolic syndrome among inpatients with schizophrenia," International Journal of Psychiatry in Medicine, vol. 38, no. 1, pp. 103-112, 2008.

[92] J. P. McEvoy, J. M. Meyer, D. C. Goff et al., "Prevalence of the metabolic syndrome in patients with schizophrenia: baseline results from the Clinical Antipsychotic Trials of Intervention Effectiveness (CATIE) schizophrenia trial and comparison with national estimates from NHANES III," Schizophrenia Research, vol. 80, no. 1, pp. 19-32, 2005.

[93] J. Bobes, C. Arango, P. Aranda, R. Carmena, M. GarciaGarcia, and J. Rejas, "Cardiovascular and metabolic risk in outpatients with schizoaffective disorder treated with antipsychotics: results from the CLAMORS study," European Psychiatry. In press.

[94] E. Fernandez-Egea, M. Bernardo, T. Donner et al., "Metabolic profile of antipsychotic-naive individuals with non-affective psychosis," The British Journal of Psychiatry, vol. 194, no. 5, pp. 434-438, 2009.

[95] L. P. Voruganti, Z. Punthakee, R. J. Van Lieshout et al., "Dysglycemia in a community sample of people treated for schizophrenia. The Diabetes in Schizophrenia in Central-south Ontario (DiSCO) study," Schizophrenia Research, vol. 96, no. 13, pp. 215-222, 2007.

[96] J. M. Goldstein, S. V. Faraone, W. J. Chen, G. S. Tolomiczencko, and M. T. Tsuang, "Sex differences in the familial transmission of schizophrenia," British Journal of Psychiatry, vol. 156, pp. 819-826, 1990.

[97] A. E. Pulver and K. Y. Liang, "Estimating effects of proband characteristics on familial risk-II. The association between age at onset and familial risk in the Maryland schizophrenia sample," Genetic Epidemiology, vol. 8, no. 5, pp. 339-350, 1991.

[98] W. Maier, D. Lichtermann, J. Minges, R. Heun, and J. Hallmayer, "The impact of gender and age at onset on the familial aggregation of schizophrenia," European Archives of Psychiatry and Clinical Neuroscience, vol. 242, no. 5, pp. 279-285, 1993. 
[99] K. S. Kendler and D. Walsh, "Gender and schizophrenia: results of an epidemiologically-based family study," British Journal of Psychiatry, vol. 167, pp. 184-192, 1995.

[100] J. M. Godstein, S. V. Faraone, W. J. Chen, and M. T. Tsuang, "Gender and the familial risk for schizophrenia. Disentangling confounding factors," Schizophrenia Research, vol. 7, no. 2, pp. 135-140, 1992.

[101] E. Cantor-Graae, T. F. McNeil, K. Sjostrom, L. G. Nordstrom, and T. Rosenlund, "Obstetric complications and their relationship to other etiological risk factors in schizophrenia: a controlled study," Journal of Nervous and Mental Disease, vol. 182, no. 11, pp. 645-650, 1994.

[102] G. Kirov, P. B. Jones, I. Harvey et al., "Do obstetric complications cause the earlier age at onset in male than female schizophrenics?" Schizophrenia Research, vol. 20, no. 1-2, pp. 117-124, 1996.

[103] R. Heun and W. Maier, "The role of obstetric complications in schizophrenia," Journal of Nervous and Mental Disease, vol. 181, no. 4, pp. 220-226, 1993.

[104] C. M. Hultman, A. Ohman, S. Cnattingius, I. M. Wieselgren, and L. H. Lindstrom, "Prenatal and neonatal risk factors for schizophrenia," British Journal of Psychiatry, vol. 170, pp. 128-133, 1997.

[105] H. Verdoux and M. Bourgeois, "A comparative study of obstetric history in schizophrenics, bipolar patients and normal subjects," Schizophrenia Research, vol. 9, no. 1, pp. 67-69, 1993. 


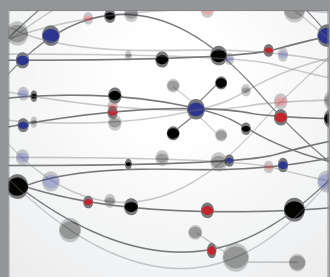

The Scientific World Journal
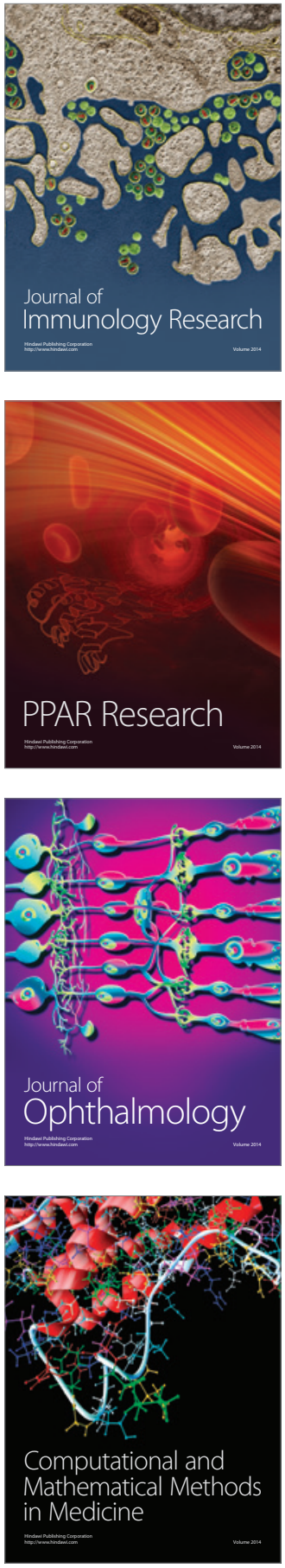

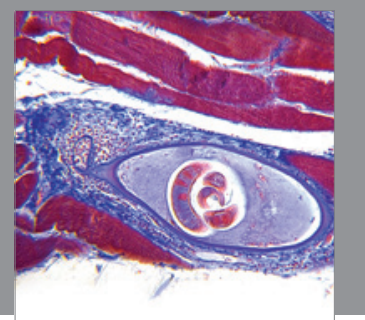

Gastroenterology

Research and Practice
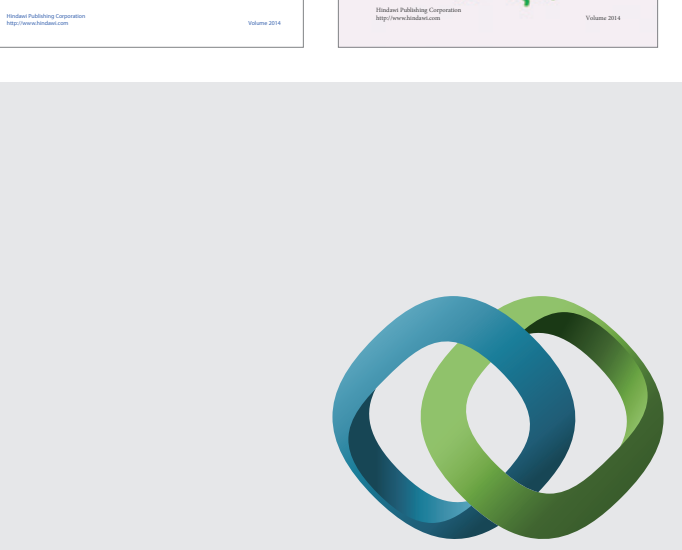

\section{Hindawi}

Submit your manuscripts at

http://www.hindawi.com
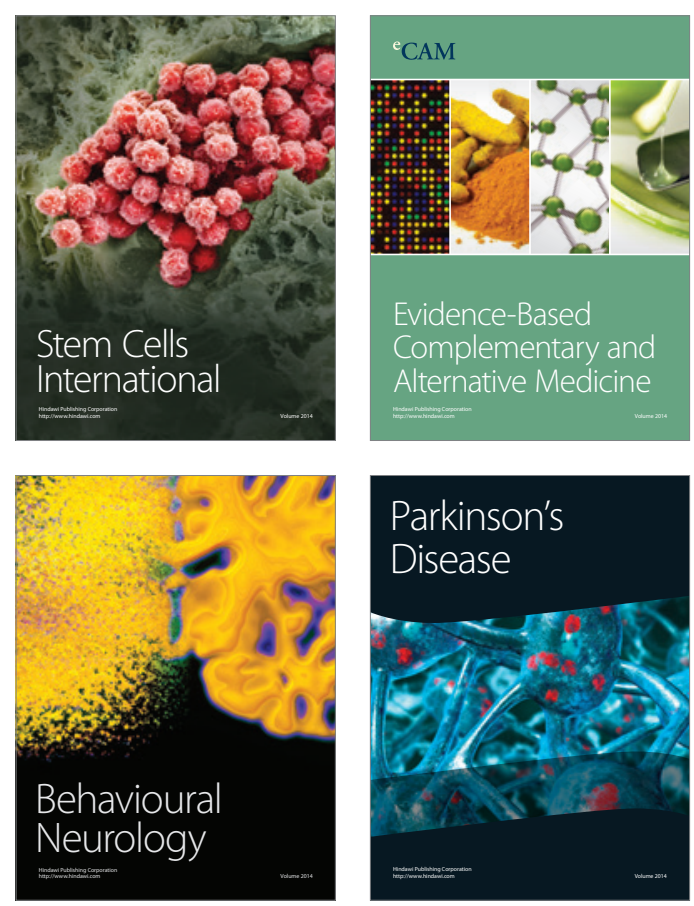

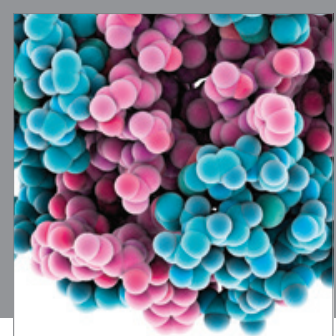

Journal of
Diabetes Research

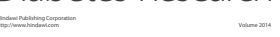

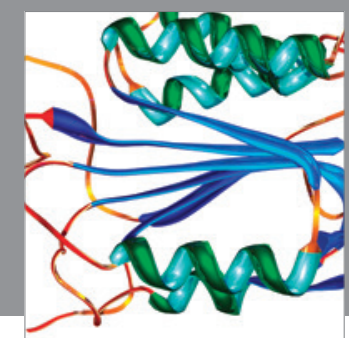

Disease Markers
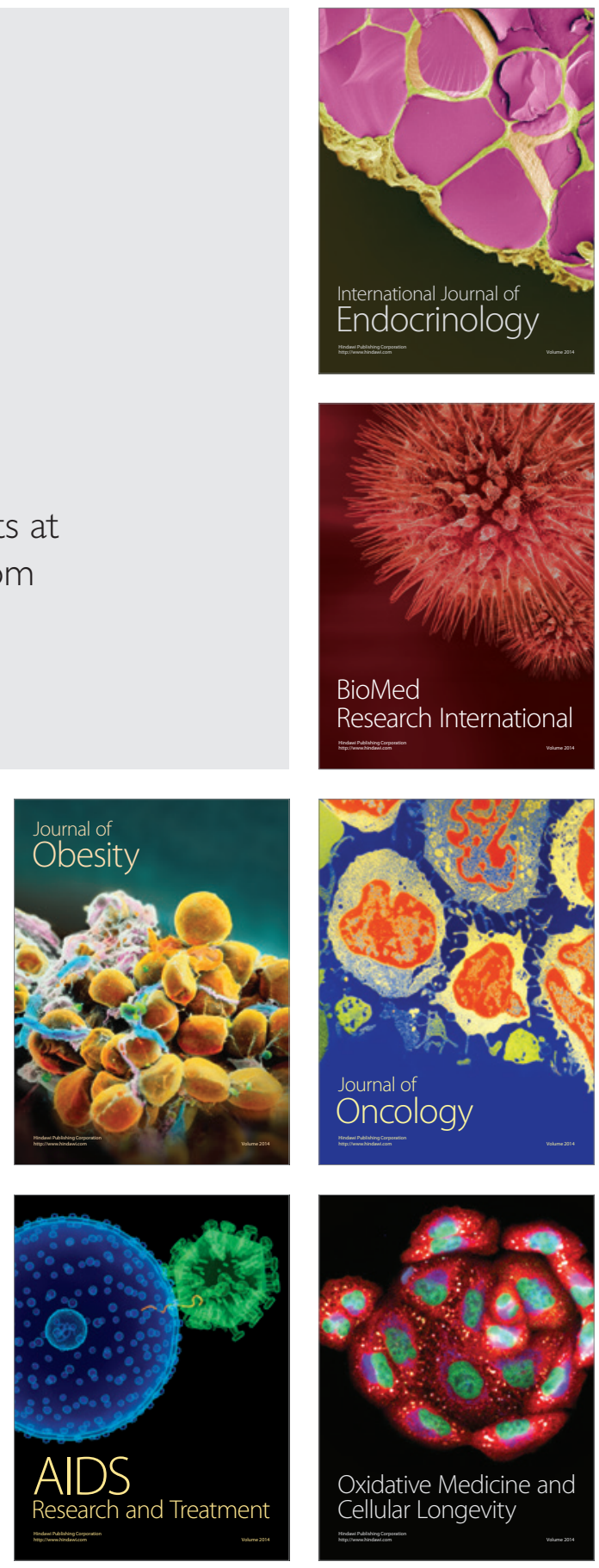